\title{
Contrasting population changes in sympatric penguin species in association with climate warming
}

\author{
JAUME FORCADA, P. N. TRATHAN, K. REID, E. J. MURPHY and J. P. CROXALL \\ British Antarctic Survey, Natural Environment Research Council, High Cross, Madingley Road, Cambridge CB3 0ET, UK
}

\begin{abstract}
Climate warming and associated sea ice reductions in Antarctica have modified habitat conditions for some species. These include the congeneric Adélie, chinstrap and gentoo penguins, which now demonstrate remarkable population responses to regional warming. However, inconsistencies in the direction of population changes between species at different study sites complicate the understanding of causal processes. Here, we show that at the South Orkney Islands where the three species breed sympatrically, the less iceadapted gentoo penguins increased significantly in numbers over the last 26 years, whereas chinstrap and Adélie penguins both declined. These trends occurred in parallel with regional long-term warming and significant reduction in sea ice extent. Periodical warm events, with teleconnections to the tropical Pacific, caused cycles in sea ice leading to reduced prey biomass, and simultaneous interannual population decreases in the three penguin species. With the loss of sea ice, Adélie penguins were less buffered against the environment, their numbers fluctuated greatly and their population response was strong and linear. Chinstrap penguins, considered to be better adapted to ice-free conditions, were affected by discrete events of locally increased ice cover, but showed less variable, nonlinear responses to sea ice loss. Gentoo penguins were temporarily affected by negative anomalies in regional sea ice, but persistent sea ice reductions were likely to increase their available niche, which is likely to be substantially segregated from that of their more abundant congeners. Thus, the regional consequences of global climate perturbations on the sea ice phenology affect the marine ecosystem, with repercussions for penguin food supply and competition for resources. Ultimately, variability in penguin populations with warming reflects the local balance between penguin adaptation to ice conditions and trophic-mediated changes cascading from global climate forcing.
\end{abstract}

Keywords: air temperature, climate warming, GAMMs, population decline, population dynamics, pygoscelid penguins, sea ice extent, South Orkney Islands

Received 31 May 2005; revised version received 21 September 2005; accepted 2 November 2005

\section{Introduction}

Some of the clearest signals of regional climate warming come from the Antarctic Peninsula (Smith et al., 1999; Vaughan et al., 2001; Gille, 2002; Cook et al., 2005), including significant long-term increases in air temperature, retreat of glaciers, and the collapse of large ice shelves. Emerging evidence suggests that warming has decreased the number of cold years with heavy winter sea ice and that as a consequence penguin populations

Correspondence: Jaume Forcada, fax + 1223-221259,

e-mail: jfor@bas.ac.uk are showing substantial concurrent population responses (Fraser et al., 1992; Fraser \& Trivelpiece, 1996; Croxall et al., 2002; Smith et al., 2003). Current hypotheses suggest that in general, in locations where species' breeding ranges overlap, sea ice reduction has produced habitat conditions more suitable for ice-intolerant species, which have increased in numbers, whereas ice-dependent species have declined. Nevertheless, contrasting trends in population processes at different sites within the Antarctic suggest that species specific responses to climate change are complex and differ regionally or even locally. Although sea ice affects penguin populations, the ecological mechanisms concerning the observed patterns of change and the nature 
of the links to climate warming are not clear (Croxall et al., 2002).

The three pygoscelid penguins, Adélie (Pygoscelis adeliae), chinstrap ( $P$. antarctica), and gentoo ( $P$. papua) penguins, are all affected by changes in sea ice extent (Fraser et al., 1992; Trathan et al., 1996; Ainley et al., 1998; Wilson et al., 2001; Clarke et al., 2002; Kato et al., 2002; Smith et al., 2003). The gentoo penguin is mainly subAntarctic with a subspecies confined to the Antarctic Peninsula. In the bulk of its range, it is a year round resident confined to inshore waters; its winter habitat on the Antarctic Peninsula is unknown. The Adélie penguin is a circum-Antarctic continental species, closely linked to ice and in winter the marginal ice zone, but extending north along the Antarctic Peninsula and Scotia Arc, effectively to the South Orkney Islands. Outside this range, it has only a small outlying population in the Southern South Sandwich Islands. The chinstrap penguin is essentially confined to the Antarctic Peninsula, its associated island groups and the South Sandwich Islands, just reaching South Georgia in the north. It occupies a niche usually regarded as complementary to the niche of the Adélie penguin in terms of marine habitat. Where the three species occur sympatrically, the primary cause affecting their ecological segregation appears to be adaptation to their preferred habitats (Lishman, 1985; Trivelpiece et al., 1987). This adaptation is mediated by specific differences in foraging and migratory behaviour, life history tactics and breeding chronology. As their preferred habitat is largely defined by the presence/absence of sea ice (Lishman, 1985; Trivelpiece et al., 1987; Trathan et al., 1996; Clarke et al., 2002; Lynnes et al., 2004), the links between sea ice and penguin population process are key to understanding population changes that occur as a consequence of regional warming.

Extensive ice cover in late spring and early summer is a physical barrier preventing the access of penguins with lower ice tolerances to the breeding colonies (Lishman, 1985; Fraser et al., 1992; Trathan et al., 1996; Ainley et al., 1998; Wilson et al., 2001; Rombolá et al., 2003; Lynnes et al., 2004). On the other hand, regional sea ice variability limits the abundance of Antarctic krill (Euphausia superba), a dominant component of the penguin diet in some regions (Fraser et al., 1992; Fraser \& Trivelpiece, 1996; Fraser \& Patterson, 1997; Lynnes et al., 2002, Fraser \& Hoffman, 2003; Lynnes et al., 2004). Sea ice modulates the factors controlling the distribution and biomass of phytoplankton that krill larvae require to ensure maximum rates of growth and recruitment (Quetin et al., 1996; Loeb et al., 1997; Ross et al., 2000; Siegel, 2000; Quetin \& Ross, 2003; Atkinson et al., 2004).

Given the strong linkages between sea ice, phytoplankton, krill and penguins, it is conceivable that the effects of global climatic anomalies on sea ice extent (e.g. White \& Peterson, 1996; Kwok \& Comiso, 2002) cascade to penguins through bottom-up control, (i.e. from prey to predators). Climate warming may change the species-specific optimum habitats through a combination of reductions in sea ice extent and increased variability in penguin food supply. Because food supply determines changes in all animal populations (Sinclair \& Krebs, 2002), major population declines are likely to result from reduced prey availability caused by the effects of warming on sea ice. In addition, population changes with warming may also occur with habitat modifications, expansions or reductions, related to changing regional sea ice conditions. Thus, our hypothesis was that concurrent population changes of the different species would result from the interaction of changes in food supply and habitat availability related to sea ice modifications with warming; and that population responses would be species-specific.

We investigated this hypothesis with abundance data from Adélie, chinstrap and gentoo penguins breeding sympatrically at Signy Island, South Orkney Islands, from 1978 to date. Signy Island provides ideal conditions for this study because: it is located at the northern limit of the distribution range of the ice-dependent Adélie penguin, at the centre of the chinstrap penguin distribution and at the southern limit of the studied gentoo penguin sub-species distribution; the summer diet of all three species is highly dominated by Antarctic krill (Lynnes et al., 2004, BAS unpublished data); and, the island is within a region where there is evidence of a strong warming trend in air temperature (Jones \& Reid, 2001) and a decreasing trend in winter fast-ice duration (Murphy et al., 1995). We investigated trends and major changes in the physical environment and in the breeding population of the three species over time. Regional trends in sea ice extent and air temperature at the South Orkneys were compared with SST in the tropical Pacific to investigate whether the response of regional penguin populations could be related to hemisphere-scale climate variability and, hence, were amenable to prediction based on global climate perturbations. We discuss our findings in the context of studies at other sites in Antarctica in order to assess common patterns in penguin population change.

\section{Materials and Methods}

\section{Data}

SST, air temperature and sea ice extent. Monthly ice-extent satellite data were obtained between January 1982 and April 2004, from the National Oceanographic and Atmospheric Administration (NOAA, U.S. Department 
of Commerce), at the U.S. National Center for Atmospheric Research (NCAR, web page: http://dss.ucar. $\mathrm{edu} /$ datasets/ds277.0/data/oiv2/mnly/data). The data were part of the OI V.2 set (Reynolds et al., 2002), and indicated the northern limit of the ice edge. For this analysis, the limit was taken as the mean of the values between longitudes $46^{\circ}-44^{\circ} \mathrm{W}$.

Monthly mean surface air temperature from Orcadas Station (Laurie Island, South Orkney Islands, $60^{\circ} 45^{\prime} \mathrm{S}$, $44^{\circ} 43^{\prime} \mathrm{W}$ ) was obtained from the data set of Jones and Reid (2001), available at: http:/ / www.antarctica.ac.uk/ met/gjma/temps.html. This data set extends over 100 years, from 1903 to 2004, shows a highly significant $(P<0.0001)$ positive annual trend $0.0200 \pm 0.0084$ $\left({ }^{\circ} \mathrm{C} \mathrm{yr}^{-1}\right)$ that is higher in the winter months $\left(0.0262 \pm 0.0179{ }^{\circ} \mathrm{C} \mathrm{yr}^{-1}\right)$, and shows that the decade of the 1990s was the warmest in the instrument record.

Monthly SST from El Niño region $3.4\left(5^{\circ} \mathrm{N}-5^{\circ} \mathrm{S}\right.$ and $\left.170^{\circ}-120^{\circ} \mathrm{W}\right)$ from 1950 to 2004 was obtained from the National Weather Service, National Center for Environmental Prediction (NCEP, NOAA, ftp:// ftpprd.ncep.noaa.gov).

Penguin data. Signy Island is an important site for the large penguin populations that breed annually at the South Orkneys. Data on breeding population size was collected annually at selected Adélie-, chinstrap- and gentoo-breeding colonies between 1978 and 2004. Data from a given breeding season are represented by the date in which chicks fledged (e.g. the split summer of $1978 / 1979$ is represented by 1979). The data consist of counts of breeding pairs collected by two or more experienced observers. We considered the total number of breeding pairs as the sum of pairs in different breeding assemblages or subcolonies, each of which was counted every breeding season throughout the time series. Additional details on data collection can be found in Croxall et al. (1988) and Trathan et al. (1996). Penguin subcolonies were defined as discrete assemblages of contiguous nests. Subcolonies were not closed demographic units despite the high level of philopatry reported in these species (Williams, 1995; Ainley, 2002), which suggest that most pairs return to breed to the same subcolony every year when breeding is not deferred.

\section{Analysis}

To assess the sensitivity and quantify the limits of penguin responses to climate variability we investigated the long-term trends of the penguin populations monitored at Signy Island; and we characterized the temporal structure of the physical environment at the South Orkneys associated with climate variability. The lag struc- ture of the physical environment was analysed in relation to the lag structure in penguin population changes.

Trends and correlations in the physical environment. Longterm trends in the air temperature and sea ice series were investigated with a seasonal decomposition based on a semiparametric regression with loess smoothing (Cleveland et al., 1990). The seasonal component was removed from each monthly series and the new sub-series was smoothed to find long-term trends through several iterations. The residuals of the seasonal and trend fits were also removed, leaving a smoothed trend filtered for residual noise. The filtered series showed the succession of anomalies over time and was used in subsequent cross-correlation analyses between the three environmental data sets. These analyses investigated teleconnections (large-scale spatial and temporal relationships) between the physical environment at the South Orkneys and the climate-oceanic variability in the tropical Pacific Ocean. In addition, we used the predictive value of the Orcadas air temperature and the sea ice extent filtered series to assess the effects of the variability in the physical environment on penguin population changes.

Trends in breeding populations of penguins. Penguin population trends were investigated using an abundance index (Fewster et al., 2000) based on generalized additive models (GAMs; Hastie \& Tibshirani, 1990). Our analysis modelled the expected penguin counts in each year at different subcolonies, of which there were 8, 11, and 10 for Adélie, chinstrap, and gentoo penguins, respectively. The expected count $\mu_{i t}$ in subcolony $i$ and year $t$, was a function of an additive predictor with a subcolony effect $\varsigma_{i}$ and a smoothed function of time $f(t)$, so that the total predicted count for $N$ subcolonies and year $t$ was

$$
\sum_{i=1}^{N} \hat{\mu}_{i t}=\exp [\hat{f}(t)] \sum_{i=1}^{N} \exp \left(\hat{\varsigma}_{i}\right) .
$$

Estimates for the smoothed functions were obtained using GAMs with a cubic spline basis and assuming a Poisson error structure. The estimates were combined in an annual abundance index curve as

$$
I(t)=\exp [\hat{f}(t)] / \exp [\hat{f}(1)]
$$

This index measured relative abundance with respect to the first year in each count series. By estimating the components of this index with GAMs, we modelled trends as a nonlinear function of time. In the GAMs, the higher the degrees of freedom selected, the more nonlinear was a fit allowed to be. Constraining 
the nonlinearity of our models by controlling the degrees of freedom allowed us to investigate both long and short-term fluctuations in penguin numbers. We selected the appropriate degrees of freedom following a sensitivity analysis.

The method of Fewster et al. (2000) allowed us to investigate population change points with a numerical analysis of second derivatives of the smoothed indices. Significant upward changes corresponded to a second derivative value above 0 and downward changes to a value below 0 . The variability of the index (represented by the $95 \%$ confidence intervals) and statistical significance of the change points ( $5 \%$ level) were obtained by bootstrapping. We generated 1999 bootstrap samples which were combinations with replacement of the $N$ subcolonies for each species and year. Because subcolonies varied in size for each species, each bootstrap sample chose subcolonies with replacement from different subcolony size categories. A new GAM, index, and second derivative analysis was produced with each bootstrap for inference purposes.

Changes in breeding populations of penguins with the environment. We developed semiparametric models derived from the mechanistic structure of the discrete time logistic models of Ricker (1954) to examine the causes of population changes and test our main hypothesis. The general model structure was

$$
R_{t}=\alpha_{0}+\sum_{m} f_{m}(N F, E F)+\varepsilon_{t},
$$

where the population size in a given year $(t+1)$ related to the population in the previous year $\left(N_{t}\right)$ as a function of endogenous forcing (negative feedback, NF) and exogenous forcing (or environment, climate, EF) and was expressed as a realized population growth rate on a $\log$ scale, $R_{t}=\log \left(N_{t} / N_{t-1}\right) ; \alpha_{0}$ was a coefficient to be estimated; and $\varepsilon_{t}$ was stochastic noise.

Our models were implemented using generalized additive mixed models (GAMM; e.g. Fahrmeir \& Lang, 2001; Rupert et al., 2003). In this context, nonlinear endogenous and climate effects could easily be modelled. Additionally, GAMMs allowed to consider penguin colony effects as random deviates of the mean population counts. See Appendix 1 for model definition and estimation details.

\section{Results}

\section{Environmental trends and correlations}

The smoothed air temperature series from Orcadas filtered for seasonality and residual noise had a periodicity in warm anomalies of approximately 3.5 years and an increasing long-term trend (Fig. 1, centre panel). This periodicity was also apparent in the positive correlation lagged approximately 3 years between air temperature and sea ice extent (Fig. 1, lower panel). The smoothed sea ice extent series showed an opposite pattern to the air temperature series and indicated a significant decrease $(P<0.001)$, which was more obvious towards the end of the instrumental record (Fig. 2, lower panel).

The highest correlation between El Niño 3.4 region SST and air temperature at Orcadas from 1950 to 2004 was negative and at a lag of 0 months (Fig. 1, top panel). It was followed by a positive correlation at an approximate lag of 18 months, suggesting a strong connection between the tropical Pacific climate and that of the South Orkney Islands. Other significant positive and negative cross-correlations occurred with an approximate periodicity of 3 to 4 years.

The CCF between El Niño 3.4 region SST and sea ice extent from 1982 to 2004 had a pattern opposed to that of the CCF with air temperature (Fig. 1, centre panel). This was explained by a high anticorrelation between surface air temperature and sea ice extent (Fig. 1, lower panel; Fig. 2 middle and lower panels). These results suggested that the ice extent at the South Orkneys closely reflected El Niño/La Niña events occurring approximately 15 months before in the tropical Pacific.

\section{Trends in penguin populations and environment forcing}

The number of breeding gentoo penguins increased significantly $(P<0.001)$ at a mean annual rate of $5.5 \%$ between 1979 and 2004. During the same period, the number of chinstrap penguins declined significantly $(P<0.001)$ at a mean annual rate of $-1.2 \%$. There was no dominant long-term trend in Adélie penguin numbers over the 26 years, although the trajectory increased significantly $(P<0.01)$ between 1979 and 1986, and declined at a mean annual rate of $-2.8 \%$ between 1987 and $2004(P<0.01)$. Over the same more recent period, the mean annual decline of chinstrap penguins was $-1.3 \%$ (Fig. 2, top panel).

The abundance index analysis indicated synchronous change points in the population trajectories of chinstrap and Adélie penguins. The most consistent changes were upturns from low population levels occurring in 1985, 1991, 1995, and 2000. Related significant changes in the gentoo penguin abundance index occurred in 1991 and 2000 (Fig. 3).

Minimum breeding population levels occurred with minima of sea ice extent observed in the same or immediately previous years. There was a remarkable parallelism in the smoothed sea ice trends and the trends in Adélie and chinstrap penguin abundance. 


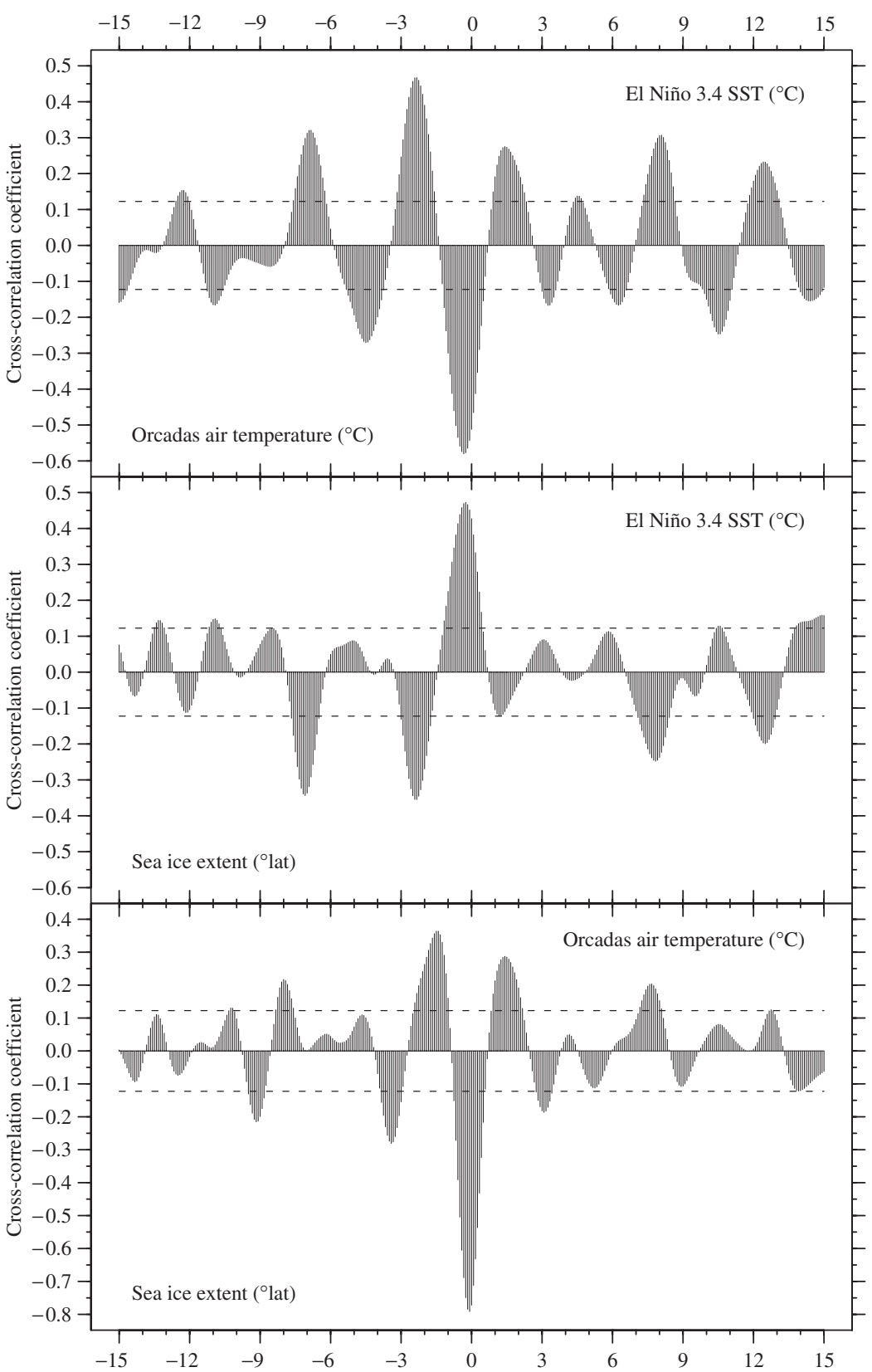

Fig. 1 Cross-correlation analysis between: monthly El Niño region 3.4 SST and surface temperature at Orcadas, from 1950 to 2003 (top panel); monthly El Niño region 3.4 SST and sea ice extent at South Orkneys from 1982 to 2004 (centre panel); and monthly surface temperature at Orcadas and sea ice extent at South Orkneys from 1982 to 2004 (bottom panel). Cross-correlations functions were computed with the aseasonal time series. The dashed lines represent standard $95 \%$ confidence limits to indicate significant correlations.

However, the chinstrap abundance index showed marked population upturns after decreases occurring in years with extensive ice cover. These were 1981 (sea ice data not shown, but see Lishman, 1985; Trathan et al., 1996), and years 1988 and 1998. In 1998 the persistence of ice cover during the chinstrap-breeding season prevented the access of researchers to colonies and the data are thus unavailable. The extensive ice cover in 1998 caused a reduced chick production in chinstrap penguins (Lynnes et al., 2004) and a low return of breeders in other colonies at the South Orkneys (Rombolá et al., 2003).

Based on the model selection algorithm, interannual population changes in gentoo penguins were best explained by changes with air temperature but not with ice. However, air temperature and sea ice extent were 


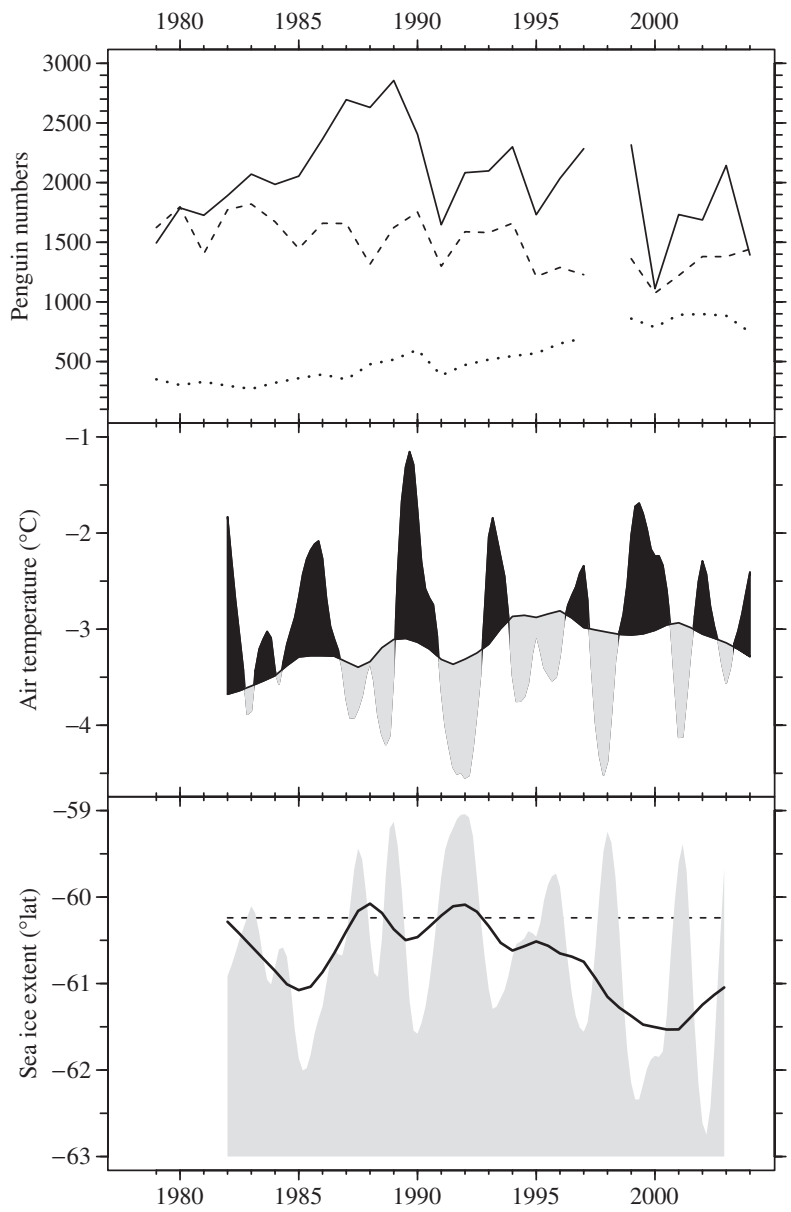

Fig. 2 Long-term variability in penguin populations and the physical environment at Signy Island, South Orkney Islands. Top panel: numbers of breeding pairs of Adélie (continuous line), chinstrap (dashed line) and gentoo penguins (dotted line) at selected study subcolonies. Center panel: Surface air temperature anomaly time series at Orcadas Station, Laurie Island, South Orkney Islands, after filtering for seasonality and residual noise; positive and negative anomalies are shown as black and gray areas respectively, above and below a long-term smoothed trend based on a loess (see methods for details) smoothing window of 5 years. Lower panel: satellite derived sea ice extent anomalies ( ${ }^{\circ}$ latitude South), averaged between longitudes $46^{\circ}$ to $44^{\circ} \mathrm{W}$, after filtering for seasonality and residual noise; the bold continuous line shows a decreasing trend, based on a loess smoothing window of 5 years; and the horizontal dashed line shows the latitude of Signy Island.

highly correlated (Fig. 1) and were likely to represent similar environmental effects on penguins. A linear increase in air temperature reduced subcolony size between years significantly $(P<0.01$; Fig. 4$)$. These effects were best modelled with a residual error correlation structure described with a moving average of order 3. The effects of subcolony size in previous seasons,

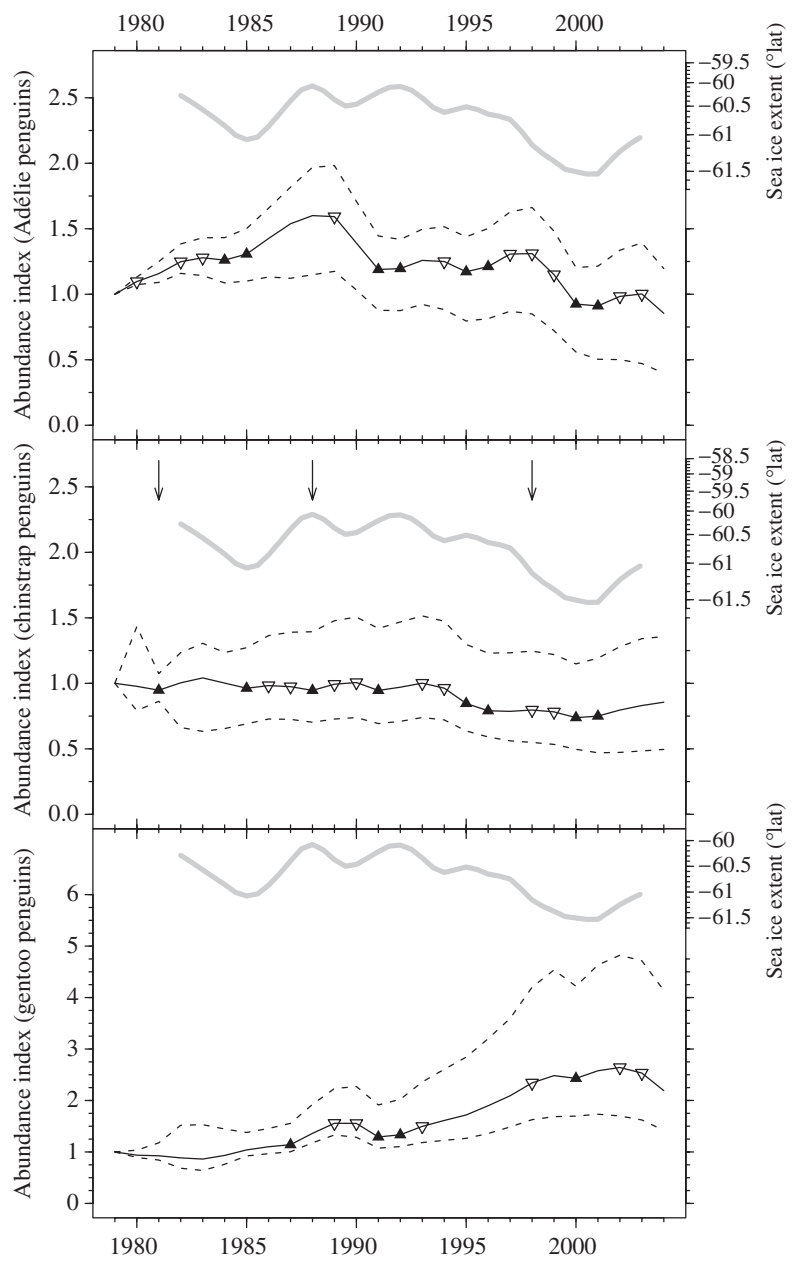

Fig. 3 Abundance indices of Adélie, chinstrap and gentoo penguins breeding at Signy Island, South Orkney Islands. Dashed lines are bootstrap 95\% confidence limits; open triangles are significant $(P<0.05)$ population downturns; full triangles are significant population upturns; and the grey thick line represents smoothed long-term trends in regional sea ice extent (as in Fig. 2). Arrows in the centre panel point to years with exceptionally extensive ice cover.

considered as direct or delayed negative feedback, did not improve the model fit, which was also not improved by including random effects for subcolony. This indicated that the size of the subcolonies did not interact with the environmental responses.

Interannual population changes of Adélie and chinstrap penguins were best modelled as the result of the interaction between the environment and the size of each subcolony at time $t-1$. For both species, the best explanatory variables were subcolony as a factor (all factor levels significant $P<0.001$ in each species and model) and sea ice extent and air temperature. Because sample size was relatively low to fit many smooth 


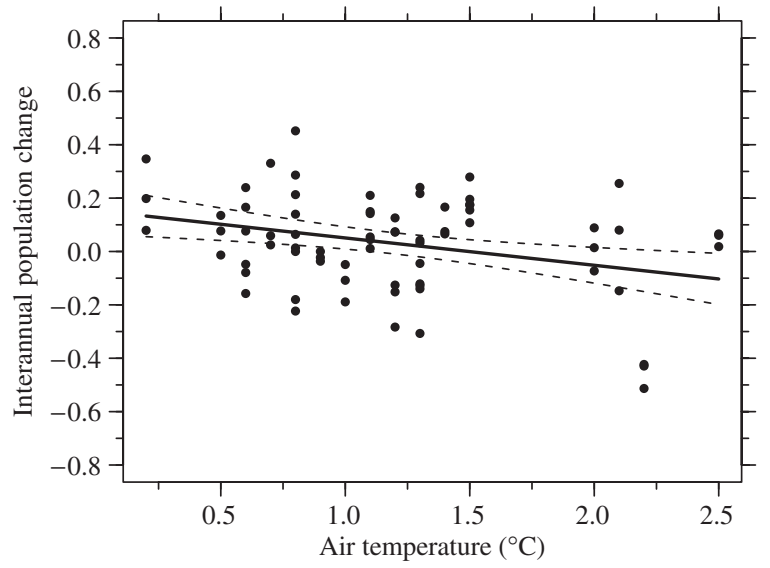

Fig. 4 Linear interannual decrease in number of breeding pairs of gentoo penguins as a function of air temperature.

functions in the same model, different models with each environmental variable and colony were fitted for Adélie and chinstrap penguins. The best options were the tensor product of sea ice extent and colony size at $t-1$, with a nonlinearity estimated as 7.2 degrees of freedom (df; approximate $\chi^{2}$ value $79.8 ; P<0.001$; adjusted $\left.R^{2}=0.21\right)$ for Adélie, and as $7.3 \mathrm{df} \quad\left(\chi^{2}=125.6\right.$; $P<0.001 ; R^{2}=0.30$ ) for chinstrap penguins. A different model with similar effects of subcolony indicated a significant interaction between air temperature and colony size at $t-1$, represented by a tensor product of the two variables with $7.0 \mathrm{df}\left(\chi^{2}=55.8 ; P<0.001\right.$; $\left.R^{2}=0.25\right)$ for Adélie, and $10.6 \mathrm{df}\left(\chi^{2}=106.1 ; P<0.001\right.$; $\left.R^{2}=0.43\right)$ for chinstrap penguins.

Environmental forcing on penguin numbers was highly linear, except for air temperature on chinstrap penguins. Most of the nonlinearity was a consequence of combined effects of direct negative feedback and the environment (Figs 5 and 6). This means that the number of breeding penguins decreased in year $t$ following increased air temperature and reduced sea ice extent at year $t-1$. There was an increase in negative feedback coupled with this environmental forcing. These feedback effects required the modelling of the residual error structure of each population trajectory as a moving average of orders 3 and 2 for Adélie and chinstrap penguins, respectively.

These results suggested the interaction between local 'ice events' mainly affecting access to breeding sites and drastic effects on penguin productivity in the years when the events occurred; and region or system-wide 'warming events' affecting levels of food availability and, thereby, impacting population processes at all levels and scales. The effects of this in relation to reduction in ice habitat were greatest for Adélie penguins and least for gentoo penguins.
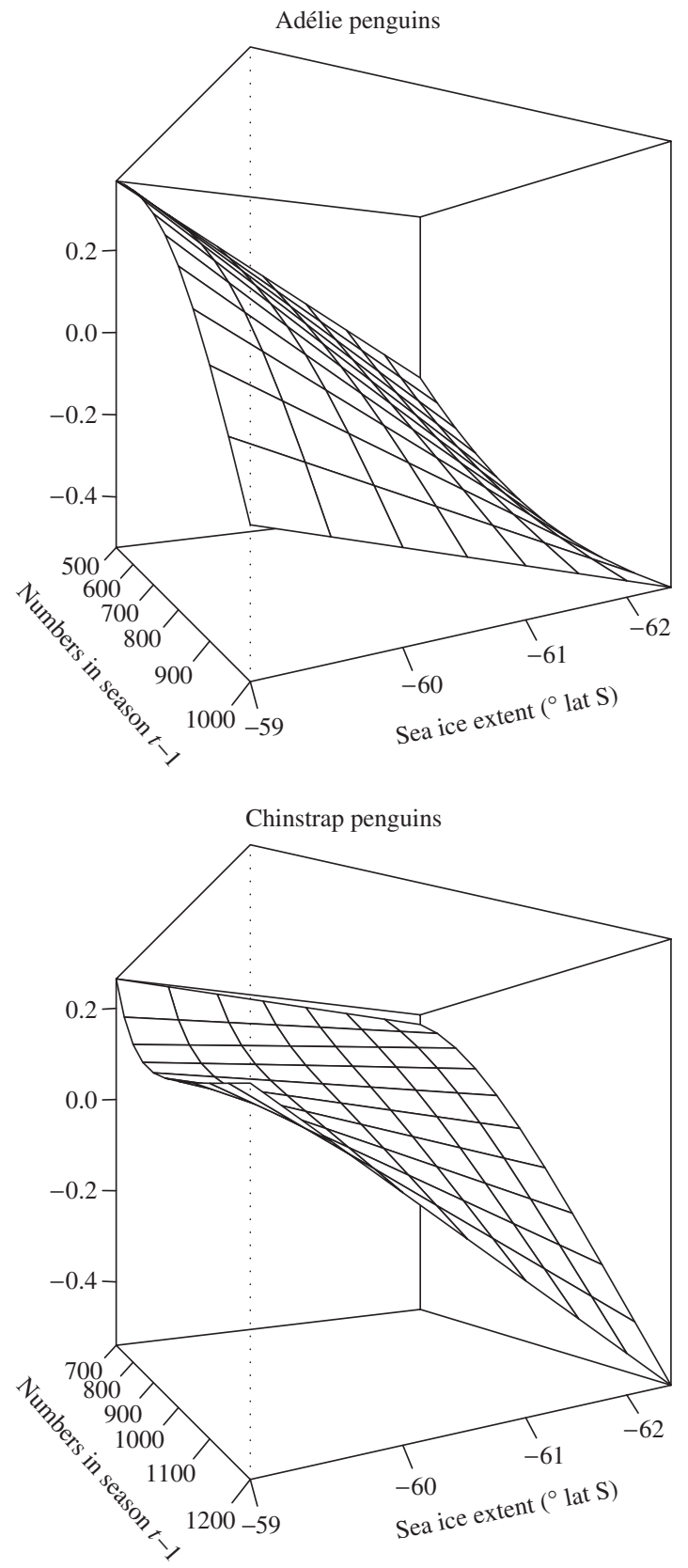

Fig. 5 Simultaneous interannual decrease in number of breeding pairs of Adélie (top panel) and chinstrap penguins (lower panel) with regional sea ice extent and numbers of breeding pairs at time $t-1$. Changes in numbers in the $z$-axis occur between consecutive seasons $t-1$ and $t$.

\section{Discussion}

Trends in warming and sea ice extent

Our analysis indicated that variability in the tropical Pacific climate was highly correlated with sea ice phenologies and regional sea ice extent at the South 

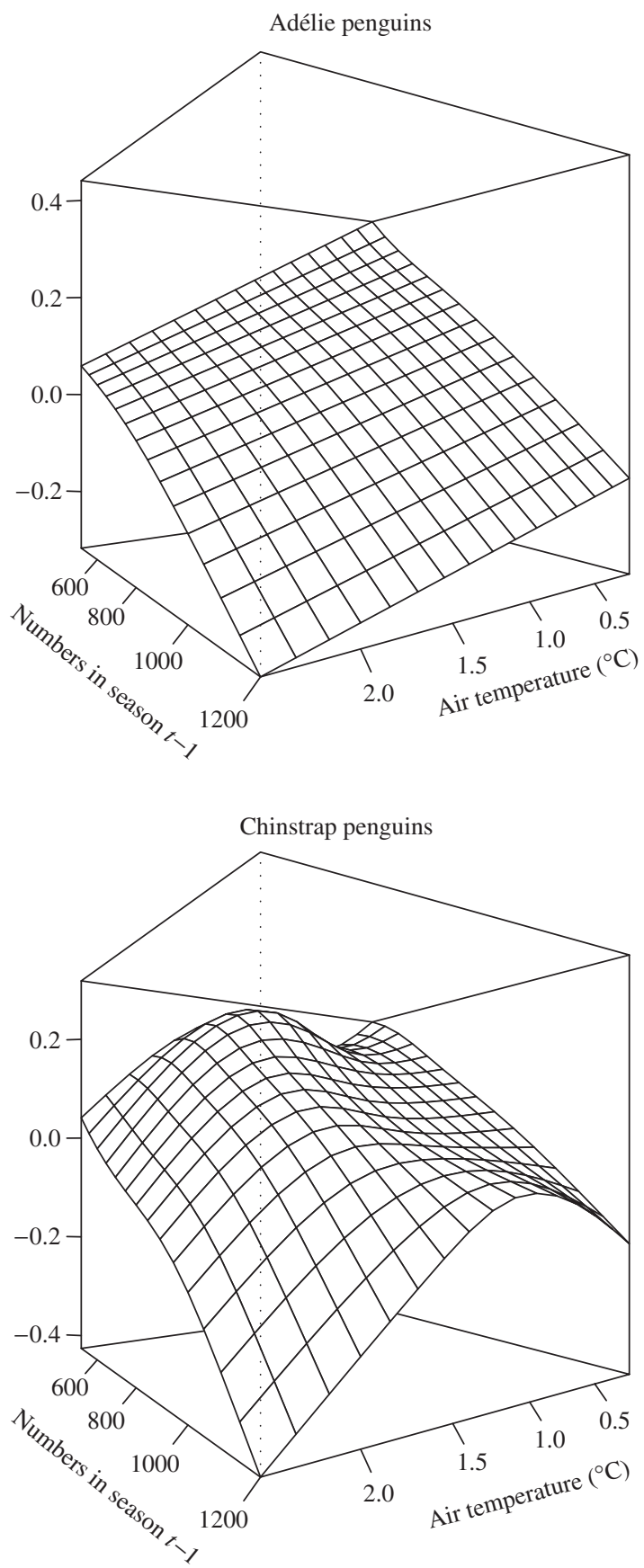

Fig. 6 Simultaneous interannual decrease in number of breeding pairs of Adélie (top panel) and chinstrap penguins (lower panel) with surface air temperature and numbers of breeding pairs at time $t-1$. Changes in numbers in the $z$-axis occur between consecutive seasons $t-1$ and $t$.

Orkney Islands. Such teleconnections have already been suggested (Murphy et al., 1995; Peterson \& White, 1998), but have not been associated with a recent decreasing trend in regional sea ice coverage at the South Orkneys. The strongest correlation between the Southern Oscilla- tion Index and the polar climate anomalies has been found in the Bellingshausen, Amundsen, and Ross Seas. These climate anomalies are associated with recent anomalies in the sea ice cover in the same sectors of the Southern Ocean, and also to the reduced sea ice concentration in the western Weddell Sea (Kwok \& Comiso, 2002). These ice concentration reductions appear to be affecting the South Orkneys and the southern Scotia Sea as part of the same global processes.

Because of the relatively short sea ice satellite record, it is unclear whether the observed decreasing trends in sea ice extent are part of natural decadal variation or indicative of global climate change. Nevertheless, our analysis showed a strong anticorrelation between air temperature and sea ice extent at the South Orkneys, and a cross-correlation pattern which suggests that the trends in both physical measurements are coupled and connected to the same global phenomena. If the unequivocal warming trends in air temperature at Orcadas (Jones \& Reid, 2001) continue to hold a strong inverse relationship with sea ice extent, it is conceivable that there will be a continuation of the decrease in the frequency of years with high sea ice and an increasing trend in average ice-free periods.

Trends in regional sea ice coverage have revealed opposing Southern Ocean climate patterns (Stammerjohn \& Smith, 1997; Vaughan et al., 2001). These trends have important implications for marine ecosystems associated with sea ice habitats. However, the implications for habitats may be different with different regional climate patterns. Therefore, the interpretation of the effects of sea ice reduction on penguin populations has to be considered first in a regional context, and then at a more global scale, in relation with global climate perturbations.

\section{Penguin population trends and environmental forcing}

Our results showed opposing population trends between gentoo penguins, which increased, and chinstrap penguins, which consistently declined over the study period. Both trajectories were observed over a period characterized by long-term warming and regional sea ice reductions, which increased in frequency in the late 1980s. At this point, the population trajectory of Adélie penguins started to decline significantly. Positive anomalies in air temperature (negative anomalies in sea ice extent) potentially resulted in similar population changes (Figs 3 and 7), suggesting the occurrence of temporary ecosystem modifications that affected the three species. Based on evidence from diet and breeding success studies of the same populations (Lynnes et al., 2004), we believe that the effects on the biological environment were directly related to the physical en- 


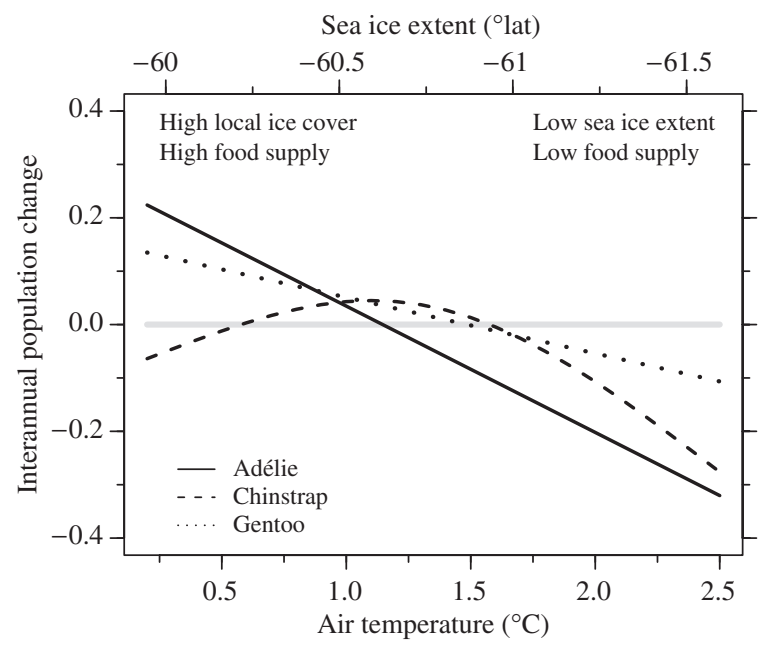

Fig. 7 Penguin population responses to the environment a Signy Island, South Orkney Islands. Responses are expressed as interannual changes in numbers of breeding pairs; a positive change is a population increase and a negative change is a population decrease.

vironment that altered the distribution and abundance of the main prey, Antarctic krill.

A study of the breeding performance and diet of chinstrap and Adélie penguins at Signy Island from 1997 to 2001 (Lynnes et al., 2004) indicated that both species had breeding failures in 2000, during the most persistent negative anomaly in sea ice extent (Fig. 2). These failures were associated with a reduction in Antarctic krill biomass, which represented over 99\% of the penguin diet in summer (Lynnes et al., 2004). That study supported the association of sea ice cycles and the persistent reduction of sea ice, with a 'senescence' of the cohorts dominating the krill populations exploited by penguins (Fraser \& Hoffmann, 2003). This process apparently led to failure of krill recruitment and reductions in krill biomass that were more apparent during the peak of negative sea ice anomalies. A study from 1987 to 1997 near Palmer Station, Anvers Island, western Antarctic Peninsula, related years of low krill abundance and poor Adélie penguin performance with similar sea ice cycles (cf. Fraser \& Hoffmann, 2003); in particular, during seasons 1990/1991 and 1994/1995, which were also poor seasons at Signy Island (Fig. 3). This low krill supply correlated with low krill densities at Elephant Island (cf. Fraser \& Hoffmann, 2003), situated $642 \mathrm{~km} \mathrm{NE}$ of Palmer Station and $498 \mathrm{~km} \mathrm{~W}$ of Signy Island. Therefore, these low krill densities concurrent with sea ice anomalies at the South Orkneys (Fig. 2, lower panel) support the connection of the biological and physical environment between the western Antarctic Peninsula and the South Orkney Islands. The parallelism in sea ice trends and numbers of chin- strap and Adélie penguins at Signy thus suggest cycles of food shortage leading to declining numbers of breeders. Because of this parallelism, the sea ice extent in year $t-1$ was more positively correlated with penguin numbers in year $t$. However, sea ice cycles starting between 3 and 4 years before year $t$ were the drivers of major krill shortage and low penguin population levels in year $t$.

\section{A conceptual framework for penguin responses to climate} warming in krill-dominated ecosystems

Our results suggest that understanding the change of penguin populations in response to the environment depends upon the consequences of local 'ice events', regional or system-wide 'warming events', and the interaction between the two types of events. Local 'ice events' mainly affected the access of penguins to breeding sites and had consequences for breeding success in the years when the events occurred, and possibly reduced recruitment in subsequent years. Regional or system-wide 'warming events' affected levels of food availability and, thereby, impacted population processes at all levels and scales, with consequences for breeding success and most likely for adult survival.

Major population changes simultaneous with climate warming are likely to result from major food web modifications and reductions in food supply. Persistent climate anomalies reducing the winter/spring sea ice extent appear to affect the recruitment and biomass of the krill exploited by penguins (see also Wilson et al., 2001; Fraser \& Hoffmann, 2003); penguin population responses are also consistent with the duration of the anomalies that affect krill; these usually become manifest during the breeding season although they may operate before arrival. For example, impacts upon the number of breeding pairs could result from interactions that affect survival and/or foraging success over the winter period prior to the breeding season (Trathan et al., 1996); this may act over a number of weeks (or months) to impact upon body condition and subsequent ability to breed.

However, the consequences for different species depend upon their affinity with ice-dominated habitats, breeding chronology, and their ability to exploit ecological niches made available through ecosystem changes that result from warming.

Adélie penguins are likely to be the species most affected in areas of prevailing maritime control of the climate regime, as are the Antarctic Peninsula and their associated Antarctic Islands. Adélie penguins prefer habitats dominated by pack-ice, and for that reason are thought to need the least amount of time in spring to occupy nest sites and rear their chicks prior to 
returning to the sea ice to molt (Ainley, 2002). With very low sea ice extent and low food availability they may experience increased intraspecific (Figs 5 and 6) and potentially interspecific competition (Lynnes et al., 2002) during the limited time that they have to complete their breeding cycle. In contrast, they will take advantage of an average or good food supply when sea ice cover outlasts the onset of the breeding seasons of their congeners, which will likely be less successful. With climate warming and continued sea ice reductions, Adélie penguins will have fewer occasions to successfully complete their breeding cycle. They will be operating under extreme conditions within their distribution and habitat preferences, which will favour their congeners. By being less buffered against the environment, their responses may be linear (e.g. Fig. 7), most likely reflecting decreases in their more variable populations trajectories (e.g. Fig. 3).

Chinstrap penguins are restricted to the maritime portion of the northern part of the Antarctic zone and to sub-Antarctic islands (Williams, 1995). They are unaffected by sea ice, which partially occupies their distribution range in summer, unless it is so extensive that it impedes the access to their breeding colonies (Fig. 3). With low ice and consequent low food supplies during their breeding season, chinstrap penguins will likely increase foraging effort. Still, they may be able to segregate their feeding range from that of Adélie penguins (Lynnes et al., 2002), given the differences in the two species breeding cycle chronologies (Trivelpiece et al., 1987; Williams, 1995). Being constrained by extreme sea ice cover and also by very low sea ice extent, chinstrap penguin breeding population responses to the environment may be less linear than those of Adélie penguins (Fig. 7). With climate warming, by being adapted to ice-free conditions they will be better buffered against the environment, their populations will be less variable (Fig. 3) and their responses to low food supplies will be nonlinear, driven by extreme events (Fig. 7). The number of years with unimpeded access to the colonies will likely increase, allowing for range expansion in areas where sea ice has receded and competition for food is low. Reductions in sea ice extent may favour the increase in founder colonies. However, with potential reductions in food supply, intraspecific competition for resources will likely increase (Figs 5 and 6) and established breeding colonies could decline.

Gentoo penguins feed close to their colonies, which are generally established in flat ice-free areas in the Antarctic zone and on sub-Antarctic islands. The long time between the egg pre-laying activities and fledging of their chicks necessitates that they remain close to their breeding sites longer than their congeners (Williams, 1995). The comparably high energy demands of their breeding cycle and the need for continuous short foraging trips at sea limit their foraging ranges in distance, but also potentially the maximum size of their breeding aggregations (Trivelpiece et al., 1987; Williams, 1995). Therefore, they exploit a different niche and a different, perhaps more constant food source than their congeners (Croxall \& Davis, 1999). With climate warming and reduced sea ice extent, their breeding ranges can expand to areas which previously provided unsuitable habitats. Small established or founder breeding colonies can grow to carrying capacity levels of their new habitats. This is likely to be the case of increases in colony size observed at the South Orkneys and other areas. However, populations will mostly be limited by shortages in the main food supply driven by sea ice cycles. Given their remarkable inability to cope with extreme food shortage (Croxall \& Davis, 1999), their responses in established colonies to environmental change will be nonlinear (e.g. Trathan et al., 2006).

\section{Contrasting regional trends and climate warming}

A number of factors associated with regional warming have been suggested as drivers of penguin population changes (e.g. Ainley, 2002), but causal mechanisms remain equivocal (Croxall et al., 2002). There is however a prevailing hypothesis that the decreasing number of cold years with heavy winter sea ice has produced habitat conditions more suitable for ice-intolerant, as opposed to ice-dependent species (Fraser et al., 1992). At Arthur Harbor (Palmer Station, Antarctic Peninsula), chinstrap, and gentoo penguins, the more ice-intolerant species, have increased, whereas the ice-dependent Adélie penguins have decreased (Smith et al., 2003). In contrast to Signy Island, which is at the centre of the chinstrap penguin distribution range and where chinstrap penguins have been slowly declining, Palmer Station is at the southernmost edge of the chinstrap distribution (Fig. 1, p. 526 in Fraser et al., 1992). This species only established founder colonies in 1977 (Smith et al., 2003) and, therefore, both numbers and intraspecific competition are likely to be low, allowing for increasing trends. Nevertheless, the same physical and biological processes now limiting Adélie and chinstrap penguins at Signy Island could affect chinstrap penguins at Palmer Station with the build up of breeding numbers over time (e.g. Fig. 5). Adélie penguins at King George Island and Anvers Island, which are not far from Palmer station, had negative population changes in 1991 and 1995 (Fraser \& Patterson, 1997; Trivelpiece \& Trivelpiece, 2001). These population downturns apparently related to low krill abundance and sea ice (Fraser \& Hoffmann, 2003) and they were concurrent with population downturns of chinstrap and Adélie 
penguins at Signy Island. Further research on the environmental consequences for chinstrap penguins at Palmer Station would help understand the common effects of global climate variability on penguin population changes.

Trends in Adélie penguins appear to have increased in other locations where food chains may be less Antarctic krill-dependent and local conditions may be more stringent than in the Antarctic Peninsula: in East Antarctica, in the Indian Ocean, many of the colonies near Syowa Station appear to have increased (Kato et al., 2002); and at the Ross Island, Ross Sea, colonies have also increased (Wilson et al., 2001). In these areas, Adélie penguin increases are attributed to improving spatial and temporal access to nesting and foraging habitats because of earlier sea ice breakout and the formation of polynyas close to land margins. Nevertheless, some of the global climate effects observed at Signy Island and the Antarctic Peninsula appear to have caused interannual reductions in Adélie penguin numbers at Ross Island, and perhaps at Syowa Station. In particular, during the climate anomalies of 1990 and 1994. El Niño-Southern Oscillation (ENSO) variability in the tropical Pacific is known to propagate through atmospheric and oceanic processes with a cyclical signal of 4-5 years (Peterson \& White, 1998). The strongly coupling of the atmosphere-ocean-sea-ice systems and the precession of ENSO anomalies reflect on sea-ice anomalies in different regions of Antarctica according to the dominant cyclical signal. These anomalies appear to affect the populations of Adélie penguins in the Ross Sea (Wilson et al., 2001). Therefore, the direct attribution of penguin trends in some regions to climate change cannot be ruled out. Some ecosystem changes occur at scales longer than the available biological records and may remain unnoticed unless studied with appropriate methods (e.g. Emslie et al., 1998). In order to understand why these changes occur, it is necessary to understand which are the optimal regional conditions for penguin populations. At a larger space and time scale, such regional changes may be put in the context of more global phenomena.

Sea ice phenology near penguin breeding colonies represents an integrated response to changes in climatic conditions. Ice break-up date generally reflects spring warming rates for the previous months. Assuming that some variability in the spatial and temporal availability of sea ice is the optimal condition, climate warming could simultaneously force an increase or decrease in penguin populations depending on what species-specific factors limit their populations (Fraser \& Trivelpiece, 1996). In areas where the penguin food supply depends on sea ice as a more permanent feature of the marine environment, climate warming is likely to cause simultaneous population declines among sympatric species. Changes in sea ice phenology may result in substantially longer ice-free seasons and in consistent trends toward late autumn freezing and earlier spring break-up. In these conditions, Adélie penguins will be less buffered against the environment and at a disadvantage to chinstrap and gentoo penguins, which are more adapted to ice-free conditions. However, chinstrap and Adélie penguins will be at a disadvantage to gentoo penguins, which may be able to exploit a different niche less affected by sea ice reductions. Ultimately, population variability will likely reflect the local balance between penguin adaptation to ice free conditions and trophic mediated changes cascading from climate forcing.

\section{Acknowledgements}

We are grateful to all the field researchers at Signy Island, South Orkney Islands who collected data and helped with these longterm monitoring studies. Mike Dunn provided invaluable information on data collection procedures. This work was carried out in support of the British Antarctic Survey DYNAMOE Discovery 2010, LTMS, Core Science Programme at South Georgia and South Orkneys.

\section{References}

Ainley DG (2002) The Adélie Penguin. Bellwether of Climate Change. Columbia University Press, Princeton, USA.

Ainley DG, Wilson PR, Barton KJ et al. (1998) Diet and foraging effort of Adélie penguins in relation to pack-ice conditions in the southern Ross Sea. Polar Biology, 20, 311-319.

Atkinson A, Siegel V, Pakhomov E et al. (2004) Long-term decline in krill stock and increase in salps within the Southern Ocean. Nature, 432, 100-103.

Berryman AA (1999) Principles of Population Dynamics and Their Applications. StanleyThornes Publishers Ltd, Cheltenham, UK.

Chatfield C (2004) The Analysis of Time Series: An Introduction, 6th edn. Chapman \& Hall/CRC, London, UK.

Clarke J, Kerry K, Irvine L et al. (2002) Chick provisioning and breeding success of Adélie penguins at Béchervaise Island over eight successive seasons. Polar Biology, 25, 21-30.

Cleveland RB, Cleveland WS, McRae JE et al. (1990) STL: A seasonal-trend decomposition procedure based on loess. Journal of Official Statistics, 6, 3-73.

Cook AJ, Fox AJ, Vaughan DG et al. (2005) Retreating glacier fronts on the Antarctic Peninsula over the past half-century. Science, 308, 541-544.

Croxall JP, Davis LS (1999) Penguins: paradoxes and patterns. Marine Ornithology, 27, 1-12.

Croxall JP, McCann TS, Prince PA et al. (1988) Reproductive performance of seabirds and seals at South Georgia and Signy Island, South Orkney Islands, 1976-1987: implications for Southern Ocean monitoring studies. In: Antarctic Ocean and Resources Variability (ed. Sahrhage D), pp. 261-285. Springer, Berlin. 
Croxall JP, Trathan PN, Murphy EJ (2002) Environmental change and Antarctic seabird populations. Science, 297, 1510-1514.

Emslie SD, Fraser W, Smith RC et al. (1998) Abandoned penguin colonies and environmental change in the Palmer Station area, Anvers Island, Antarctic Peninsula. Antarctic Science, 10, 257268.

Fahrmeir L, Lang S (2001) Bayesian inference for generalized additive mixed models based on Markov random field priors. Applied Statistics, 50, 201-220.

Fewster RM, Buckland ST, Siriwardena GM et al. (2000) Analysis of population trends for farmland birds using generalized additive models. Ecology, 81, 1970-1984.

Fraser WR, Hoffmann EE (2003) A predator's perspective on causal links between climate change, physical forcing and ecosystem response. Marine Ecology Progress Series, 265, 1-15.

Fraser WR, Patterson DL (1997) Human disturbance and longterm changes ni Adelie penguin populations: a natural experiment at Palmer Station, Antarctic Peninsula. In: Antarctic Communities, Species, Structures and Survival (eds Battaglia B, Valencia J, Walton DWH), pp. 445-452. Cambridge University Press, Cambridge, UK.

Fraser WR, Trivelpiece WZ (1996) factors controlling the distribution of seabirds: winter-summer heterogeneity in the distribution of Adélie penguin populations. In: Foundations for Ecological Research West of the Antarctic Peninsula (eds Ross RM, Hoffman EE, Quetin LB), pp. 257-272. American Geophysical Union, Washington, DC (Antarctic Research Series, vol. 70).

Fraser WR, Trivelpiece WZ, Ainley DG et al. (1992) Increases in Antarctic penguin populations: reduced competition with whales or a loss of sea ice due to environmental warming? Polar Biology, 11, 525-531.

Gille ST (2002) Warming of the Southern Ocean since the 1950s. Science, 295, 1275-1277.

Hastie TJ, Tibshirani RJ (1990) Generalized Additive Models. Monographs on Statistics and Applied Probability 43. Chapman \& Hall, London, UK.

Jones PD, Reid PA (2001) A Data Bank of Antarctic Surface Temperature and Pressure Data. ORNL/CDIAC-27 NDP-032. Carbon Dioxide Information Analysis Center, Oak Ridge National Laboratory, U.S. Department of Energy, Oak Ridge, Tennessee. Available at: http://www.antarctica.ac.uk/met/ gjma/temps.html.

Kato A, Ropert-Coudert Y, Naito Y (2002) Changes in Adé lie penguin breeding populations in Lü tzow-Holm Bay, Antarctica, in relation to sea-ice conditions. Polar Biology, 25, 934-935.

Kwok R, Comiso JC (2002) Southern Ocean climate and sea ice anomalies associated with the Southern Oscillation. Journal of Climate, 15, 487-501.

Lishman GS (1985) The comparative breeding biology of Adélie and chinstrap penguins Pygoscelis adeliae and Pygoscelis antarctica at Signy Island, South Orkney Islands. Ibis, 127, 84-99.

Loeb V, Siegel V, Holm-Hansen O et al. (1997) Effects of sea-ice extent and krill or salp dominance on the Antarctic food web. Nature, 387, 897-900.

Lynnes AS, Reid K, Croxall JP et al. (2002) Conflict or coexistence? Foraging distribution and competition for prey between Adélie and chinstrap penguins. Marine Biology, 141, 1165-1174.
Lynnes AS, Reid K, Croxall JP (2004) Diet and reproductive success of Adélie and chinstrap penguins: linking response of predators to prey population dynamics. Polar Biology, 27, 544-554.

Murphy EJ, Clarke A, Symon C et al. (1995) Temporal variation in Antarctic sea-ice: analysis of a long term fast-ice record from the South Orkney Islands. Deep Sea Research I, 42, 1045-1062.

Peterson RG, White WB (1998) Slow oceanic teleconnections linking the Antarctic Circumpolar Wave with the tropical El Niño-Southern Oscillation. Journal of Geophysical Research, 103, 24573-24583.

Pinheiro JC, Bates DM (2000) Mixed-Effects Models in S and S-Plus. Springer-Verlag, New York, USA.

Quetin LB, Ross RM (2003) Episodic recruitment in Antarctic krill Euphausia superba in the Palmer LTER study region. Marine Ecology Progress Series, 259, 185-200.

Quetin LB, Ross RM, Fraser TK et al. (1996) Factors affecting distribution and abundance of zooplankton, with an emphasis on Antarctic krill (Euphausia superba). In: Foundations for Ecological Research West of the Antarctic Peninsula (eds Ross RM, Hoffman EE, Quetin LB), pp. 357-371. American Geophysical Union, Washington, D.C., (Antarctic Research Series, vol. 70).

R Development Core Team (2003) R: A Language and Environment for Statistical Computing. R Foundation for Statistical Computing, Vienna, Austria ISBN 3-900051-00-3, URL http://www. R-project.org.

Reynolds RW, Rayner NA, Smith TM et al. (2002) An improved in situ and satellite SST analysis for climate. Journal of Climate, 15, 1609-1625.

Ricker WE (1954) Stock and recruitment. Journal of the Fisheries Research Board of Canada, 11, 559-623.

Rombolá E, Marschoff E, Coria N (2003) Comparative study of the effects of the late pack-ice break-off on chinstrap and Adélie penguins' diet and reproductive success at Laurie Island, South Orkney Islands, Antarctica. Polar Biology, 26, 41-48.

Ross RM, Quetin LB, Baker KS et al. (2000) Growth limitation in young Euphausia superba under field conditions. Limnology and Oceanography, 45, 31-43.

Rupert D, Wand MP, Carroll RJ (2003) Semiparametric Regression. Cambridge University Press, Cambridge, UK.

Siegel V (2000) Krill (Euphausiacea) demography and variability in abundance and distribution. Canadian Journal of Fisheries and Aquatic Sciences, 57, 151-167.

Sinclair ARE, Krebs CJ (2002) Complex numerical responses to top-down and bottom-up processes in vertebrate populations. Philosophical Transactions of the Royal Society of London B, 357, 1221-1231.

Smith RC, Ainley D, Baker et al. (1999) Marine ecosystem sensitivity to climate change. BioScience, 49, 393-404.

Smith RC, Fraser WR, Stammerjohn SE (2003) Climate variability and ecological response of the marine ecosystem in the Western Antarctic Peninsula (WAP) region. In: Climate Variability and Ecosystem Response at Long-Term Ecological Research Sites (eds Greenland D, Goodin DG, Smith RC), pp. 158-173. Oxford University Press, Oxford, UK.

Stammerjohn SE, Smith RC (1997) Opposing southern ocean climate patterns as revealed by trends in regional sea ice coverage. Climatic Change, 37, 617-639. 
Stenseth NC (1999) Population cycles in voles and lemmings: density dependence in a stochastic world. Oikos, 87, 427-461.

Trathan PN, Croxall JP, Murphy EJ (1996) Dynamics of Antarctic penguin populations in relation to inter-annual variability in sea ice distribution. Polar Biology, 16, 321-330.

Trathan PN, Murphy EJ, Forcada J et al. (2006) Physical forcing in the southwest Atlantic: ecosystem control. In: Top Predators in Marine Ecosystems (eds Boyd IL, Wanless S, Camphuysen CJ), pp. 28-45. Cambridge University Press, Cambridge, UK.

Trivelpiece WZ, Trivelpiece SG (2001) Commission for the Conservation of Antarctic Marine Living Resources, Working Group on Ecosystem Monitoring and Management, Paper 21.

Trivelpiece WZ, Trivelpiece SG, Volman NJ (1987) Ecological segregation of Adélie, gentoo, and chinstrap penguins at King George Island, Antarctica. Ecology, 68, 351-361.

Vaughan DG, Marshall GJ, Connelly WM et al. (2001) Perspectives: climate change. Devil in the detail. Science, 293, 17771779 .

White WB, Peterson RG (1996) An Antarctic circumpolar wave in surface pressure, wind, temperature and sea-ice extent. Nature, 380, 699-702.

Williams TD (1995) The Penguins: Spheniscidae. Oxford University Press, Oxford, UK

Wilson PR, Ainley DG, Nur N et al. (2001) Adélie penguin population change in the pacific sector of Antarctica: relation to sea-ice extent and the Antarctic Circumpolar Current. Marine Ecology Progress Series, 213, 301-309.

Wood SN (2004a) Low rank scale invariant tensor product smooths for Generalized Additive Mixed Models. Technical Report of the Department of Statistics, University of Glasgow, UK. Available at: http://www.stats.gla.ac.uk/Research/TechRep2004/04-13.pdf.

Wood SN (2004b) Tensor product smooth interaction terms in Generalized Additive Mixed Models. Available at http:// www.stats.gla.ac.uk/\%7Esimon/simon/papers/tgamm.pdf.

\section{Appendix 1}

Our general model structure was

$$
N_{t+1}=N_{t} \exp [f(N F, E F)],
$$

expressed as a realized population growth rate on a log scale, was

$$
R_{t}=\alpha_{0}+\left[\sum_{k=1}^{T} f_{i k}\left(N_{t-k} \times \text { climate }_{t-k}\right)\right]+\varepsilon_{t},
$$

where $N_{t-k}$ was density in $k$ breeding seasons preceding $t$ and represented direct or delayed negative feedback; climate is used here as a short notation term for ice extent and air temperature. The central term $\sum_{k=1}^{T} f_{i k}\left(N_{t-k} \times\right.$ climate $\left._{t-k}\right)$ denotes combined additive and interaction effects, $\sum_{k=1}^{T} f_{1 k}\left(N_{t-k}\right)+f_{2 k}\left(\right.$ climate $\left._{t-k}\right)+$ $f_{3 k}\left(N_{t-k}\right.$, climate $\left._{t-k}\right)$.
Similar models, developed for analysis in a time series context (Berryman, 1999; Stenseth, 1999), assumed homogeneity in the $\varepsilon_{t}$ terms, which is seldom observed. Instead, we modelled heteroscedasticity by considering different subcolony variances, $\operatorname{var}\left(\varepsilon_{t}\right)=$ $\sigma^{2} \delta_{\xi_{t}}^{2}$, with $\varsigma+1$ parameters to represent $N$ total subcolonies. We modelled serial correlation structures of $\varepsilon_{t}$ in the form of ARMA models (autoregressive-moving average models; Chatfield, 2004), $\varepsilon_{t}=\sum_{i=1}^{p} \phi_{i} \varepsilon_{t-i}+$ $\sum_{j=1}^{q} \theta_{j} a_{t-j}+a_{t}$. These general error structures combine autoregressive errors of lag $p, \operatorname{AR}(p)$, and moving averages of order $q, \operatorname{MA}(q)$, which can also be tested separately as simplified nested structures.

In an GAMM context, the general model was

$$
R_{i j}=X_{i} \theta+\left[\sum_{k=1}^{K} f_{1 k}\left(N_{i-k} \times \text { climate }_{i-k}\right)\right]+Z_{i} b_{j}+\varepsilon_{i j}
$$

where $X_{i}$ was the $i$ th row of the fixed-effects model matrix, $\theta$ was a vector of fixed parameters; the $f_{k}$ were smooth functions of the different covariates, $Z_{i}$ was the $i$ th row of the random-effects model matrix, $b \sim N(0, \psi)$ was a vector of coefficients of random effects with covariance matrix $\psi$; and $\varepsilon \sim N(0, \Lambda)$ was a vector of residual gaussian errors with covariance matrix $\Lambda$. Each penguin subcolony of each species was treated as a random deviate of the mean population growth rate. Thus, each $R_{i j}$ corresponded to the $i$ th seasonal observation of colony $j$ of $N$ possible colonies by species, and the random effects for subcolonies were included as part of the vector $b_{j}$ of coefficients.

We used GAMM methods of Wood (2004a, b), which represent the smooth function separated into an unpenalized component, treated as fixed effects, and a smoothed component, treated as random effects. Such framework allowed for interaction terms using tensor product smooths, which are multivariate smooths with separate degrees of smoothing in different covariate directions.

Models were fitted with package mgcv of software R (R Development Core Team, 2003) contributed by Simon N. Wood. Model fitting used routine lme, which uses restricted maximum likelihood estimation (REML), and other facilities from package nlme of Pinheiro and Bates (2000). We used AIC to test for random effects by colony; homoscedasticity and suitable error correlation structures in $\varepsilon_{i j}$ were investigated with residual and autocorrelation plots in addition to AIC differences of multiple competing models. The degree of smoothing in the $f_{k}$ terms was selected by generalized cross validation. 